\title{
Evaluation of diabetic patients after three month use of continuous subcutaneous insulin infusion, dispensed by a protocolled form at outpatient reference clinic of Taguatinga Regional Hospital
}

Leonardo Garcia Miranda', Hermelinda Cordeiro Pedrosa', Roberta Kelly Menezes Maciel Falleiros', Renata de Moraes Oliveira', Monica Tolentino', Luiz Augusto Casulari²

\begin{abstract}
Objective: To evaluate the data of continuous subcutaneous insulin infusion protocol (CSII) for diabetics waived by the Health State Secretariat of Distrito Federal (HSSDF) and therapeutic responses three months after the transfer of multiple daily injections regimen for CSII. Subjects and methods: Eighty patients ( 49 female) took part in this experimental study, mean age and disease duration were 27.9 years and 13 years, respectively; $96 \%$ patients had type 1 diabetes mellitus. Results: The entire sample (ECO) and 3 subgroups (group 1 - A1c decrease, group $2-A 1 c$ stable, and group $3-A 1 c$ increase), stratified according to $a \geq 0.5 \%$ change in $A 1 c$, were analyzed. Group 1 involved $64 \%$ of the patients. The ECO showed a significant A1c decrease: MDI $8.1 \pm 1.4 \%$ vs. CSII $7.3 \pm 0.9 \%, p<0.0001$ ( $0.8 \%$ difference pro CSII therapy). Group 1 demonstrated an A1c decrease from $8.7 \%$ to $7.3 \%$ (1.4\% difference). Group 2 mean A1c was $7.1 \%$. Rate of hypoglycemia ( $<50 \mathrm{mg} / \mathrm{dL}$ ) decreased $61 \%$ in the ECO and $79 \%$ in Group 2. Conclusion: This study reinforces the safety and efficacy of CSII with a robust $\mathrm{A} 1 \mathrm{c}$ reduction and hypoglycemia. The pioneer care HSSDF ambulatory attests to be achievable the free dispensing by Unified Health System (UHS) following a protocol, and this approach results in less wastage to the patient and represents a rational policy of therapy with CSII for UHS. Arch Endocrinol Metab. 2015;59(1):23-8
\end{abstract}

Keywords

Type 1 diabetes mellitus; multiple daily injections; insulin pump; continuous subcutaneous insulin infusion; hypoglycemia, Unified Health System (UHS-SUS)
1 Endocrinology Unit, Research Centre, Taguatinga Regional Hospital, Brasília, DF, Brazil ${ }^{2}$ Section of Endocrinology, University Hospital of Brasilia, Brasília, DF, Brazil

Correspondence to:

Leonardo Garcia Miranda

Área Especial, 24, Setor "C" Norte

72115-700 - Taguatinga, DF, Brazil

Igarciam@ig.com.br

Received on Oct/1/2013

Accepted on Nov/24/2014

DOI: 10.1590/2359-3997000000005

\section{INTRODUCTION}

$\mathrm{T}$ he need to maintain glucose as close to normal as possible in diabetic is a crucial condition to prevent chronic complications associated with the disease. Thus, the fundamental of treatment management of diabetes mellitus type 1 (DMl) is the "physiological replacement of insulin", and the main examples are therapy with multiple daily injections (MDI) and the continuous subcutaneous insulin infusion (CSII) (1).

One parameter of the goals of glycemic control is glycosylated hemoglobin (Alc) less than 7\% (1). However, this goal was not easy achieved in DMl previous studies: only $7 \%$ of 4,750 patients in Scotland (2), 13\% in Australia (3) and $11.6 \%$ in Brazil (4). Thus, several specialty societies recognize that CSII is an effective therapeutic option in the treatment of DMl and particular cases of type 2 diabetes (DM2) $(5,6)$.

Besides the failure to obtain good control with MDI (Alc $\leq 7.0 \%$ ) or poor secondary control to the presence of recurrent Ketoacidosis (6), other indications of CSII are severe hypoglycemia characterized by loss of consciousness, seizures or need assistance from others; unrecognized hypoglycemia (dysautonomia) in which the patient does not recognize the symptoms of hypoglycemia by lack of noradrenergic response; unstable glycemic control, with extreme swings in blood glucose with MDI, for example, before autonomic gastroparesis (6).

The CSII can be discontinuous if there were sustained improvement in Alc concentrations, improve- 
ment in the frequency and severity of hypoglycemia, psychiatric contraindications and recurrent skin infections or if the patient decides to return to MDI therapy. However, in most centers, the discontinuation rate is low, around $5 \%(1)$.

The CSII has been using at the Endocrinology Unit (Endo) of the Taguatinga Regional Hospital (HRT) since 2008, the year the CSII outpatient clinic was set up. This was a pioneering initiative of the public health system of Brazil - Unified Health System (UHS-SUS), initially for clinical evaluation of diabetics who managed the equipment CSII using legal action.

In 2009, during a workshop regarding the CSII implementation use in Brasilia, the Coordination of Education Program and Control of Diabetes (CEPCD) of the Health State Secretariat of Distrito Federal (HSSDF), currently the Coordination Center of Diabetes (CCD), presented to coordinators of regional CEPCD of HSSDF the Protocol CSII based on HRT experience (7). The Protocol, in its initial phase at that time, showed impressive results: the reduction of the legal actions with exclusion rate of $33 \%$ for medical indications inadequate, among other causes (7).

One of the duties of scientific and specialty societies is to establish standards and procedures for the proper use and guide the provision in public health as well, taking into account the real indications, safety and efficacy of devices and systems for therapy among diabetic people which include CSII. In this scenario, the CCD has emerged nationally as a pioneer in the CSII provision to its users in accordance to the guidelines of the Brazilian Diabetes Society - SBD (2008) (8) and American Diabetes Association - ADA (2004) (9).

The aim of this study was to evaluate protocol data of CSII dispensation for diabetics in HSSDF, in outpatients treated in Endo/HRT, and therapeutic responses three months after the transfer scheme from MDI to CSII, in relation to frequency of episodes of severe hypoglycemia and total, and metabolic control with the analysis of glycosylated hemoglobin.

\section{SUBJECTS AND METHODS}

This is a prospective, experimental study. Data was evaluated in the treatment of patients with DM before and after three months of change MDI scheme for CSII. All patients using the CSII which were treated at outpatients reference clinic for CCD/HSSDF, in Endo/ HRT were included.
Anthropometric, laboratory, and capillary glucose data were collected from patient previous forms of inclusion and/or follow-up to use the CSII or by attendance at the assessment or reassessment three months after beginning therapy with CSII. The following data were collected: clinical history, age, laboratory tests, weight, height, body mass index (BMI), and blood pressure (BP). Before starting the CSII therapy, the diabetic was evaluated according to the protocol for the use of CSII/HSSDF, for Alc, total hypoglycemia and severe hypoglycemia with MDI therapy.

Evaluations of Alc (HPLC method, Bio-Rad, Brazil) after venous blood samples and following the reference values of $4.0 \%$ to $6.5 \%$. The Alc results after the implementation of CSII were compared to those obtained with the MDI by analysis of three groups: Alc decrease above $0.5 \%$; Alc stable, with a variation of less than $0.5 \%$; and Alc increase.

Diabetic patients were also divided into two groups according to Alc concentrations before using CSII: group A - Alc equal to or greater than $8.0 \%$ and group B with Alc basal low than $8.0 \%$, to determine the benefits of CSII therapy.

The total number of hypoglycemic events $(<70$ $\mathrm{mg} / \mathrm{dL})$, severe events $(<50 \mathrm{mg} / \mathrm{dL})$, and the number of self-monitoring of blood glucose (SMBG) were obtained via software management with the diabetes Accu-Chek $360^{\circ \circledast}$ (Roche Diagnostics) or by analysis of the glucose meters when the glucose meters in use was not been by standardized model for HSSDF.

The inclusion criteria were patients using the CSII who have been treated in outpatients reference clinic for CCD/HSSDF in Endo/HRT. Patients presenting with any one of the following criteria have been excluded: 1) CSII use before inclusion in the protocol; 2 ) inability to understand the nature, scope and possible consequences of the study and/or evidence of uncooperative attitude; 3 ) any condition that increases the risk of the patient or decrease the chance of obtaining satisfactory data to achieve the objectives of the study; and 4) not performing the measurement of Alc in the study period.

Statistical analysis has been performed with SAS version 9.2. Data has been expressed as mean \pm standard deviation (SD). We used the paired Student t test for comparison of variables before (MDI) and after CSII therapy. To observe specific behaviors, the Wilcoxon nonparametric test has been applied in stratified subgroups (Alc decreased, stable or increased). The analy- 
sis of variance (ANOVA) was performed to compare the mean baseline characteristics between groups stratified (age, time since diagnosis, and BMI) and gender (time of diagnosis, BP and SMBG) and the Tukey test was applied too. The level of significance has been set at $\mathrm{p} \leq 0.05$.

\section{RESULTS}

Eighty-eight patients were evaluated; however, eight were excluded because they have been already using CSII before inclusion in the protocol. Regarding the 80 included patients, seventy $(88 \%)$ received CSII treatment by simple internal application by the counsel of HSSDF and $10(13 \%)$ via legal actions though court orders.

The patient attended came from both public and private care with the referral of a specialist. Referrals are only accepted from patients followed by endocrinologists and appropriate treatment like regimen of MDI in use of insulin analogues and carbohydrate counting.

As shown in table 1 , the majority of patients (96\%) had DMl, two (2.5\%) had DM secondary to pancreatitis and one (1.5\%) had DM2. Females predominated $(61.2 \%)$, aged between 2 and 72 years and the time of diagnosis of DM ranged from 2 to 43 years, with no statistical difference between genders. The BMI ranged from underweight and class 1 obesity (16.9 to $33.2 \mathrm{~kg} / \mathrm{m}^{2}$ ). The majority of patients had normal blood pressure and the frequency of SMBG (average/ month/day) at the analysis moment was $5.37 \pm 2.0$, similar between genders for both parameters.

The average of Alc decreased significantly: $0.8 \%$ after three months of change to CSII therapy. Table 2 shows the sample behavior in the analysis of Alc after CSII use. The groups showed no significant difference in age, DM duration and BMI.

Table 2 also presents the frequency of hypoglycemic events. Fourteen individuals (17.5\%) were excluded due to improperly configured glucometer at baseline and/or inability of the analysis by the software. A reduction of $37 \%$ was observed with a significant difference $(\mathrm{p}=0.001)$ for total hypoglycemia and $61 \%$ for severe hypoglycemia $(\mathrm{p}=0.001)$. In group with stable Alc, there was an improvement of overall hypoglycemia $(42 \%, \mathrm{p}=0.04)$ and severe $(79 \%, \mathrm{p}=0.03)$, and in the group that increase $\mathrm{Alc}$, there was a robust reduction of total hypoglycemic $(66 \%, \mathrm{p}=0.004)$ and severe $(74 \%, \mathrm{p}=0.001)$.
Table 1. Characteristics of diabetic patients included in the program of continuous subcutaneous insulin infusion

\begin{tabular}{lccc}
\hline Characteristics & Female (\%) & Male (\%) & Total (\%) \\
\hline Diabetics n(\%) & $49(62)$ & $31(38)$ & $80(100)$ \\
Type 1 diabetes n(\%) & 47 & 30 & $77(96)$ \\
Secundary diabetes n(\%) & 1 & 1 & $2(2,5)$ \\
$\begin{array}{l}\text { Type } 2 \text { diabetes n(\%) } \\
\text { Age - years (mean } \pm \text { SD) }\end{array}$ & $29.7 \pm 14$ & $25.1 \pm 17$ & $27.9 \pm 15.4$ \\
$\begin{array}{l}\text { Time since diagnostic - years } \\
\text { (mean } \pm \text { SD) }\end{array}$ & $14.8 \pm 8.8$ & $11.6 \pm 9.1$ & $13.6 \pm 9.1$ \\
$\begin{array}{l}\text { Body mass index - kg/m² } \\
\text { (mean } \pm \text { SD) }\end{array}$ & $22.7 \pm 3.6$ & $22 \pm 3.7$ & $22.6 \pm 3.7$ \\
$\begin{array}{l}\text { Systolic blood pressure - } \\
\text { mmHg (mean } \pm \text { SD) }\end{array}$ & $114.8 \pm 16$ & $117.9 \pm 20$ & $116.1 \pm 18$ \\
$\begin{array}{l}\text { Diastolic bood pressure - } \\
\text { mmHg (mean } \pm \text { SD) }\end{array}$ & $70.6 \pm 10$ & $67.2 \pm 14$ & $69.3 \pm 12$ \\
$\begin{array}{l}\text { Self-monitoring - mean/day/ } \\
\text { month (mean } \pm \text { SD) }\end{array}$ & $5.38 \pm 1.6$ & $5.34 \pm 1.9$ & $5.37 \pm 2.0$ \\
\hline Bas & & & \\
\hline
\end{tabular}

Basal characteristics between the genders (time since diagnosis, blood pressure and selfmonitoring) were not statistically significant.

Data obtained from the Central coordination of diabetes - HSSDF - Program of therapy and monitoring.

Regarding the analysis of groups according to Alc above or below $8.0 \%$ before CSII. Thirty-nine (49\%) patients had baseline Alc greater than or equal to $8.0 \%$ (group A) and showed a significant reduction of Alc (1.4\%) after three months of use of CSII, decreased from $9.0 \%$ to $7.6 \%(\mathrm{p}=0.0001)$. The forty-one patients (51\%) who had baseline Alc lower of $8.0 \%$ (group B) showed a decrease in Alc after three months of CSII, from $0.16 \%$ with an average reduction from $7.1 \%$ to $7.0 \%$ with no statistical significance $(\mathrm{p}=0.24)$.

As shown in table 3 , regarding to hypoglycemic events in MDI group, there was significant reduction for severe hypoglycemia $(62 \%-\mathrm{p}=0.05)$. In CSII group, the total reduction of hypoglycemia was higher $(47 \%-\mathrm{p}=0.001)$ as well as severe hypoglycemia $(60 \%$ $-\mathrm{p}=0.001)$.

\section{DISCUSSION}

As it can be seen in the present results, starting the CSII use and keeping it for three months had large beneficial effects in relation to previous use of MDI. The most important benefit were the significant mean reduction in Alc of $0.8 \%(\mathrm{p}<0.0001)$. That probably occurs because Alc decreased or remained stable in $82.4 \%$ of patients and increased only in $17.6 \%$ of them. The decrease in Alc was more significant in patients with reduced control prior, in other words, patients with Alc 
Table 2. Reviews of blood concentrations of glycosylated hemoglobin (A1c) in response to treatment with the continuous subcutaneous insulin infusion (CSII)

\begin{tabular}{|c|c|c|c|c|}
\hline & Total & $\begin{array}{c}\text { Decrease } \\
\text { (decrease } \\
\text { A1c } \\
\geq 0.5 \% \text { ) }\end{array}$ & $\begin{array}{c}\begin{array}{c}\text { Stable } \\
\text { (decrease }\end{array} \\
\text { A1c } \\
<0.5 \% \text { ) }\end{array}$ & $\begin{array}{c}\text { Increase } \\
\text { (increase } \\
\text { A1c) }\end{array}$ \\
\hline Diabetics n(\%) & 80 & $51(63,7 \%)$ & $15(18,7 \%)$ & $14(17,5 \%)$ \\
\hline $\begin{array}{l}\text { Age - years } \\
\text { (mean } \pm \text { SD) }\end{array}$ & $27.9 \pm 15.4$ & $28.2 \pm 15.6$ & $28.9 \pm 14$ & $25.9 \pm 16.6$ \\
\hline $\begin{array}{l}\text { Gender female/ } \\
\text { male (n) }\end{array}$ & $49 / 31$ & $31 / 20$ & $9 / 6$ & $9 / 5$ \\
\hline $\begin{array}{l}\text { Time since } \\
\text { diagnostic } \\
\text { - years } \\
\text { (mean } \pm \text { SD) }\end{array}$ & $13.6 \pm 9.1$ & $13.5 \pm 8.8$ & $15 \pm 9.9$ & $12.5 \pm 9.7$ \\
\hline $\begin{array}{l}\text { Body mass index } \\
-\mathrm{kg} / \mathrm{m}^{2} \text { (mean } \\
\pm \mathrm{SD} \text { ) }\end{array}$ & $22.6 \pm 3.7$ & $22.5 \pm 3.9$ & $23.5 \pm 4.0$ & $22.3 \pm 3.2$ \\
\hline $\begin{array}{l}\text { A1c (\%) in MDI } \\
\text { (mean } \pm \text { SD) }\end{array}$ & $8.1 \pm 1.4$ & $8.7 \pm 1.33$ & $7.3 \pm 0.8$ & $6.8 \pm 0.8$ \\
\hline $\begin{array}{l}\text { A1c (\%) in CSIl }{ }^{\dagger} \\
(\text { mean } \pm \text { SD) }\end{array}$ & $7.3 \pm 0.9^{a}$ & $7.3 \pm 0.9^{b}$ & $7.1 \pm 0.7^{c}$ & $7.5 \pm 0.6^{d}$ \\
\hline $\begin{array}{l}\text { Diabetics with } \\
\text { hypoglycemia (n) }\end{array}$ & 66 & 39 & 14 & 13 \\
\hline $\begin{array}{l}\text { Hypoglycemia } \\
-\mathrm{MDI} \\
(\text { mean } \pm \mathrm{SD})\end{array}$ & $18.7 \pm 16.4$ & $13.4 \pm 12$ & $24.6 \pm 16.9$ & $28.6 \pm 21.7$ \\
\hline $\begin{array}{l}\text { Hypoglycemia } \\
- \text { CSII } \\
\text { (mean } \pm S D)\end{array}$ & $11.9 \pm 7.9^{e}$ & $11.8 \pm 8^{\dagger}$ & $14.3 \pm 7.3^{g}$ & $9.8 \pm 7.6^{\mathrm{h}}$ \\
\hline $\begin{array}{l}\text { Severe } \\
\text { hypoglycemia } \\
-\mathrm{MDI} \\
(\text { mean } \pm \mathrm{SD} \text { ) }\end{array}$ & $5.3 \pm 8.8$ & $4.1 \pm 5.8$ & $7.6 \pm 15.4$ & $6.5 \pm 6.6$ \\
\hline $\begin{array}{l}\text { Severe } \\
\text { hypoglycemia } \\
- \text { CSII } \\
\text { (mean } \pm \text { SD) }\end{array}$ & $2.1 \pm 3.0^{i}$ & $2.4 \pm 3.5^{j}$ & $1.57 \pm 1.6^{k}$ & $1.7 \pm 2.7$ \\
\hline
\end{tabular}

Baseline characteristics (age, time since diagnostic and BMI) were no statistically significant between groups. $\mathrm{P}$ values representing the comparison between MDI and CSII to A1c: ${ }^{a} \mathrm{p}<$ $0.0001,{ }^{b} p<0.0001,{ }^{c} p=0.21,{ }^{d} p=0.02 ;{ }^{~}$ total hypoglycemia (mean/month) $(<70 \mathrm{mg} / \mathrm{dL})$ : ${ }^{e} p=0.001, e^{f} p=0.44,{ }^{9} p=0.04,{ }^{h} p=0.004 e^{\S}$ severe hypoglycemia $(\leq 50 \mathrm{mg} / \mathrm{dL})$ : ${ }^{\prime} p=0.001,{ }^{\prime} p=0.008,{ }^{k} p=0.03,{ }^{\prime} p=0.001$.

Table 3. Hypoglycemic episodes per month during multiple daily injections (MDI) regimen and continuous subcutaneous insulin infusion (CSII)

\begin{tabular}{lccc}
\hline Events & MDI group & CSIl group & p \\
\hline $\begin{array}{l}\text { Hypoglycemia }(<70 \mathrm{mg} / \mathrm{dL}) \\
\text { A1c initial }<8.0 \%\end{array}$ & $23 \pm 17.8$ & $12.1 \pm 8.5$ & 0.001 \\
A1c initial $\geq 8.0 \%$ & $14.7 \pm 1$ & $11.6 \pm 7.5$ & 0.20 \\
$\begin{array}{l}\text { Severe hypoglycemia } \\
(\leq 50 \mathrm{mg} / \mathrm{dL})\end{array}$ & & & \\
A1c initial $<8.0 \%$ & $5.2 \pm 5.4$ & $2.1 \pm 3.4$ & 0.001 \\
A1c initial $\geq 8.0 \%$ & $5.5 \pm 11.2$ & $2.1 \pm 2.7$ & 0.05 \\
\hline
\end{tabular}

Data presented as mean $\pm \mathrm{SD}$. equal to or greater than $8.0 \%$. In addition, total events and serious hypoglycemic events decreased significantly with the use of CSII with respect to the time of MDI.

These CSII results are consistent with those observed in meta-analysis $(10,11)$ and prior comparing studies with multiple daily injections $(12,13)$. However, in a literature review, it was found that Alc and average glucose levels are slightly lower or similar between CSII and MDI (14).

A meta-analysis that included 52 studies involving 1,547 patients showed improvements in glycemic control with reduced Alc and blood glucose levels with the CSII, compared with the traditional conventional insulin therapy or MDI (10). In another meta-analysis of RCTs regarding DMl (11), 301 patients were selected for use CSII and 299 for insulin injections. The difference in Alc was $0.51 \%$, and the mean glucose was more favorable for diabetics with CSII. Although the difference was small, the authors concluded that this could help to reduce the risk of vascular complications (11).

In the present study, we compared the assessment of Alc between previous use of MDI and CSII. A previous case-control study showed that the average Alc was lower with CSII use as described herein and that the sustained improvement after one year of treatment was more difficult to be achieved with the MDI (12). The results of the present study were similar to result of another previous study (13). There was a decrease of $-0.51 \%$ in Alc for the total cohort comparing to the previous use of MDI, but this result was more evident in prepuberal $(-0.48 \%)$ and young adults $(-0.76 \%)$ than in adolescents $(-0.26 \%)(13)$.

We observe that the response of Alc is more pronounced in those with CSII than in those diabetics patients with poor prior control of their disease. That is, most DM patients with Alc of $8.0 \%$ had a significant reduction $(\mathrm{p}=0.000 \mathrm{l})$, but those with lower $\mathrm{Alc}$ had not had a significant effect $(\mathrm{p}=0.24)$ on Alc. This is in agreement with other studies that showed better control of Alc in diabetic patients with a history of poor glycemic control $(13,15)$.

The effectiveness of intensive treatment, which includes the CSII, seems to decrease with the lowest frequency of SMBG and dose adjustments (16). In this sense, in a multicenter, randomized, controlled crossover, it was found that the continuous monitoring of glucose was associated with a decrease of Alc in DMl that are using CSII. This is probably due to the adjustment of insulin therapy (17). Diabetic patients in this study un- 
derwent an average of $2.0 \pm 5.37$ times/day. This was similar to some authors (16) but higher than others that only used the measure of 13 times per week (18).

Hypoglycemia is a cause of stress and anxiety which can affect wellbeing and worsen the quality of life of patients with DMl: $35-40 \%$ who have a regular episode of severe hypoglycemia requiring others' assistance (1). Hypoglycemia limits the effectiveness of intensive insulin therapy (19). The results of this study showed an average reduction of $37 \%$ of total hypoglycemia and $61 \%$ in severe hypoglycemic events. This reduction was more evident in group $2(79 \%)$ that had Alc stable and group $3(74 \%)$ who had worsening of Alc. These results can be considered excellent since the American Diabetes Association considered satisfactory reduction of 10 to $20 \%$ of severe hypoglycemia (20).

Hypoglycemia is less common with CSII compared to $\operatorname{MDI}(10,14)$. The reduction of hypoglycemic events was significantly $(\mathrm{p}=0.01)$ in nearly $50 \%$ in the patients using the CSII compared to MDI (12). It was reported that the frequency of severe hypoglycemic events decreased with CSII compared to MDI from 138 to 22 events per 100 patient-years during the first year and remained significantly lower during the four-year follow-up (15).

However, other studies showed no difference between the frequencies of hypoglycemic episodes. In a meta-analysis evaluating the frequency of hypoglycemia between CSII and MDI authors found no significant difference in severe or night hypoglycemia, in adolescents and adults, but in children there was a higher frequency of hypoglycemia (19). Glycemia below the amount considered hypoglycemic collected by control glucometers and symptomatic hypoglycemia were not different between the two methods (21). However, five patients who had frequent episodic hypoglycemic improved with CSII (21).

In studies with DM2, the use of CSII was associated with better metabolic control, and the rate of hypoglycemia was similar to the use of three daily injections of lispro and NPH (22). The improvement in Alc was also observed with greater intensity in type 2 diabetics with poor control and persisted during the six years of use CSII (23). However, other studies have shown that the use of MDI over the CSII no significant difference Alc and episodes of hypoglycemia in type 2 diabetes $(18,24)$.

The normoglycemia is associated with reduced risk of macrovascular and microvascular complications in
DMl (25). However, despite the considerable efforts of patients and health professionals, only a minority of patients can achieve Alc concentrations within the target range $(2,3,4)$. The use of the CSII therapy reduces Alc without an increase in hypoglycemic events compared with the MDI (26), and is recommended for the improved metabolic control (27).

The vast majority of diabetic patients treated at the CSII clinic of Endo/HRT received equipment and inputs via simple internal application directly on the HSSDF without the need for legal action. This latter is usually accompanied without adequate specialized assessments $(28,29)$. This fact fills one with the official guidelines recommended by SBD, for the profile of the ideal candidate for therapy (30). In principle, it is considered a good candidate for therapy with that motivation to achieve tight glycemic control and financial resources available for the use of this technology or access to government programs that provide coverage for this feature. Other requirements would be motivation to learn the general principles of selfcontrol of diabetes, ability to perform carbohydrate counting and proportional adjustments of insulin doses, and willingness and ability to operate correctly the equipment and adhere to strict recommendations on its use (30).

It appears that the HSSDF filed the assessment, benefited the local population, and optimized the use of resources allocated for this purpose. The results of this study obtained at the CSII outpatient reference clinic of HSSDF, highlighted by the robust reduction of Alc concentrations and the number of severe hypoglycemia cases assure these facts. These parameters are critical and of great relevance to consolidate the current protocol based on national and international guidelines. They also confirm the success of the pioneering activity of first CSII outpatient clinic in the country which, by means of a proper protocol and selection, has proved the access to therapy with CSII in the Brazilian UHS be possible to achieve with positive results and benefits to the population.

Financial source: none.

Acknowledgements: we would like to thank all participating patients and health care team at the Taguatinga Regional Hospital for their ongoing commitment to quality care for our patients.

Disclosure: no potential conflict of interest relevant to this article was reported. 


\section{REFERENCES}

1. Pickup JC, MB, Phil D. Insulin-pump therapy for type 1 diabetes mellitus. N Engl J Med. 2012;366:1616-24.

2. Govan L, Wu O, Briggs A, Colhoun HM, Fischbacher CM, Leese $\mathrm{GP}$, et al. Achieved levels of $\mathrm{HbA} 1 \mathrm{c}$ and likelihood of admission in people with type 1 diabetes in the Scottish population. Diabetes Care. 2011;34(9):1992-7.

3. Bryant W, Greenfield JR, Chisholm DJ, Campbell LV. Diabetes guidelines: easier to preach than practice? Med J Aust. 2006;185(6):305-9.

4. Gomes MB, Coral M, Cobas RA, Dib SA, Canani LH, Nery M, et al. Prevalence of adults with type 1 diabetes who meet the goals of care in daily clinical practice: a nationwide multicenter study in Brazil. Diabetes Res Clin Pract. 2012;97(1):63-70.

5. Phillip M, BattelinoT, Rodriguez H, DanneT, Kaufman F; European Society for Paediatric Endocrinology; Lawson Wilkins Pediatric Endocrine Society; International Society for Pediatric and Adolescent Diabetes; American Diabetes Association; European Association for the Study of Diabetes. Use of insulin pump therapy in the pediatric age-group: consensus statement from the European Society for Paediatric Endocrinology, the Lawson Wilkins Pediatric Endocrine Society, and the International Society for Pediatric and Adolescent Diabetes, endorsed by the American Diabetes Association and the European Association for the Study of Diabetes. Diabetes Care. 2007;30(6):1653-62.

6. Pinto MS, Calliari LE, Damiani D, Tschiedel B, Puñales M. Diagnóstico e tratamento do diabetes tipo 1. Posicionamento Oficial SBD $2012 \mathrm{n}^{\circ}$ 1. Disponível em: http://www.diabetes.org.br/images/stories/pdf/diagnostico-e-tratamento-dm-posicionamentoda-sbd-2012.pdf. Acesso em: 17 março, 2013.

7. Pedrosa HC, Miranda LG, Prado FA, et al. SICl - Sistema de infusão contínua de insulina (bomba) e a aplicabilidade de uma abordagem protocolada no SUS, DF: avaliação preliminar. Arq Bras Endocrinol Metab. 2009;53(Suppl 4):S461.

8. SBD. Diretrizes da Sociedade Brasileira de Diabetes de 2008. Disponível em: http://www.diabetes.org.br/educacao/docs/Diretrizes_SBD_2008_MAR_12.pdf. Acesso em: 1 março, 2012.

9. American Diabetes Association: continuous subcutaneous insulin infusion (position statement) Diabetes Care 2004;(Suppl 1):S110.

10. Weissberg-Benchell J, Antisdel-Lomaglio J, Seshadri R. Insulin pump therapy - A meta-analysis. Diabetes Care. 2003;26:107987.

11. Pickup J, Mattock M, Kerry S. Glycaemic control with continuous subcutaneous insulin infusion compared with intensive insulin injections in patients with type 1 diabetes: meta-analysis of randomized controlled trials. BMJ. 2002;324:1-6.

12. Boland EA, Grey M, Oesterle A, Fredrickson L, Tamborlane WV. Continuous subcutaneous insulin infusion: a new way to lower risk of severe hypoglycemia, improve metabolic control, and enhance coping in adolescents with type I diabetes. Diabetes Care. 1999;22(11):1779-84.

13. Nimri R, Weintrob N, Benzaquen H, Ofan R, Fayman G, Phillip M. Insulin pump therapy in youth with type 1 diabetes: a retrospective paired study. Pediatrics. 2006;117(6):2126-31.

14. Pickup J, Keen H. Continuous subcutaneous insulin infusion at 25 years: evidence base for the expanding use of insulin pump therapy in type 1 diabetes (review). Diabetes Care. 2002;25:593-8.

15. Wainstein J, Metzger M, Boaz M, Minuchin O, Cohen Y, Yaffe A, et al. Insulin pump therapy vs. multiple daily injections in obese Type 2 diabetic patients. Diabet Med. 2005;22(8):1037-46.
16. Chantelau E, Spraul M, Mühlhauser I, Gause R, Berger M. Longterm safety, efficacy and side-effects of continuous subcutaneous insulin infusion treatment forType 1 (insulin-dependent) diabetes mellitus: a one center experience. Diabetologia. 1989;32(7):421-6.

17. Battelino $T$, Conget $I$, Olsen $B$, Schütz-Fuhrmann I, Hommel E, Hoogma R, et al. The use and efficacy of continuous glucose monitoring in type 1 diabetes treated with insulin pump therapy: a randomised controlled trial. Diabetologia. 2012;55(12):3155-62.

18. ReznikY, Cohen O. Insulin pump for type 2 diabetes: use and misuse of continuous subcutaneous insulin infusion in type 2 diabetes. Diabetes Care. 2013;36:S219-25.

19. Fatourechi MM, Kudva YC, Murad MH, Elamin MB, Tabini CC, Montori VM. Clinical review: Hypoglycemia with intensive insulin therapy: a systematic review and meta-analyses of randomized trials of continuous subcutaneous insulin infusion versus multiple daily injections. J Clin Endocrinol Metab. 2009;94(3):729-40.

20. Courrèges JP, Donnet JP, Gouet $D$, Jan $P$, Amin $K$, Clavel $S$, et al. Résultats métaboliques obtenus à 2 ans sous pompe à insuline ambulatoire chez des diabétiques de type 2 en échec d'insulinothérapie optimisée (Abstract). Diabetes Metab. 2012;38:A98 [in French].

21. Ng Tang Fui S, Pickup JC, Bending JJ, Collins ACG, Keen H, Dalton N. Hypoglycemia and counterregulation in insulin-dependent diabetic patients: a comparison of continuous subcutaneous insulin infusion and conventional insulin therapy. Diabetes Care. 1986;9:221-7.

22. Berthe E, Lireux B, Coffin C, Goulet-Salmon B, Houlbert D, Boutreux $S$, et al. Effectiveness of intensive insulin therapy by multiple daily injections and continuous subcutaneous infusion: a comparison study in type 2 diabetes with conventional insulin regimen failure. Horm Metab Res. 2007;39:224-9.

23. Reznik Y, Morera J, Rod A, Coffin C, Rousseau E, Lireux B, et al. Efficacy of continuous subcutaneous insulin infusion in type 2 diabetes mellitus: a survey on a cohort of 102 patients with prolonged follow-up. Diabetes TechnolTher. 2010;12(12):931-6.

24. Raskin P, Bode BW, Marks JB, Hirsch IB, Weinstein RL, McGill JB, et al. Continuous subcutaneous insulin infusion and multiple daily injection therapy are equally effective in type 2 diabetes: a randomized, parallel-group, 24-week study. Diabetes Care. 2003;26(9):2598-603.

25. Nathan DM, Cleary PA, Backlund JY, Genuth SM, Lachin JM, OrchardTJ, et al.; Diabetes Control and Complications Trial/Epidemiology of Diabetes Interventions and Complications (DCCT/EDIC) Study Research Group. Intensive diabetes treatment and cardiovascular disease in patients with type 1 diabetes. $\mathrm{N}$ Engl $\mathrm{J}$ Med. 2005;353(25):2643-53.

26. Chaturvedi N. The burden of diabetes and its complication: trends and implications for intervention. Diabetes Res Clin Pract. 2007;76(Suppl 1):S3-12.

27. American Diabetes Association. Standards of medical care in diabetes--2011. Diabetes Care. 2011;34(Suppl 1):S11-61.

28. Cannon LCR. Ações judiciais impetradas para a obtenção de medicamentos e tratamentos especiais: a judicialização da saúde. Brasília Med. 2012;49(3):147-9.

29. Karnikowski MGO, Silva KM, Salgado FXC, Novaes MRCG. Aspectos farmacoeconômicos das ações judiciais impetradas na Secretaria de Estado de Saúde do Distrito Federal. Brasília Med. 2012;49(3):170-9.

30. Minicucci W, Figueiredo Alves ST, Araújo LR, Pimazoni-Netto A. O papel da bomba de insulina nas estratégias de tratamento do diabetes. Posicionamento Oficial SBD 2007 n 6. Rev Bras Med. 2007;Suppl 6. 